\title{
Report from the Executive Committee Meeting in Yerevan, Armenia 11-13th October 2019
}

Richard Elwes, EMS Publicity Officer and Sjoerd Verduyn Lunel, EMS Secretary

Last Autumn, the EMS Executive Committee gathered at Yerevan State University (YSU), on the generous invitation of the Armenian Mathematical Union (AMU). On Friday evening, the meeting was addressed by Yuri Movsisyan, President of the AMU, who told us about its history. Mathematics in Armenia dates back to the 7th century scholar Anania Shirakatsi whose textbook on Arithmetic ("Tvabanutyun") is preserved in Yerevan's Matenadaran (Institute of Ancient Manuscripts). The AMU, however, is of more recent birth, having been founded in 1991 by a group of mathematicians at YSU and the Academy of Sciences of Armenia. Its first President was Alexander Talalyan. Since 1993, the AMU has been an adhering organisation of the IMU, and since 2016 a member society of EMS. It currently has around 250 members throughout Armenia and the diaspora. As well as the annual AMU session, it often organises special events. Recently, 2018 was a notable year, with a series of international activities for researchers and students to mark the 120th anniversary of the leading Austrian-Armenian mathematician Emil Artin, the 90th anniversary of Sergey Mergelyan, and the 100th anniversary of Mkhitar Djrbashian.

\section{Officers' reports and membership}

After a welcome from the Chair, EMS President Volker Mehrmann, and some preliminary business, the meeting got underway with his report on his recent activities (most of which feature separately later in this report). $\mathrm{He}$ drew special attention to ongoing discussions about Open Access involving both EMS Press and the publishing houses of other learned societies, as a response to Plan S. (See Mehrmann et al, EMS Newsletter, December 2019.)

The EMS Treasurer, Mats Gyllenberg then reported on the state of the society's finances, including the arrangements with EMS Press (the newly rebooted EMS Publishing House based in Berlin, see next page). Overall the EMS finances continue to be healthy, although with expenditure for scientific projects in 2019 below the allocated budget, the EC approved his proposal to transfer funds into the EMS portfolio.

The EMS Secretary, Sjoerd Verduyn Lunel, then delivered his report, including on preparations for the next EMS Council (see below).

EMS Vice-President Betül Tanbay delivered her report, including in her capacity as liaison with the Inter-

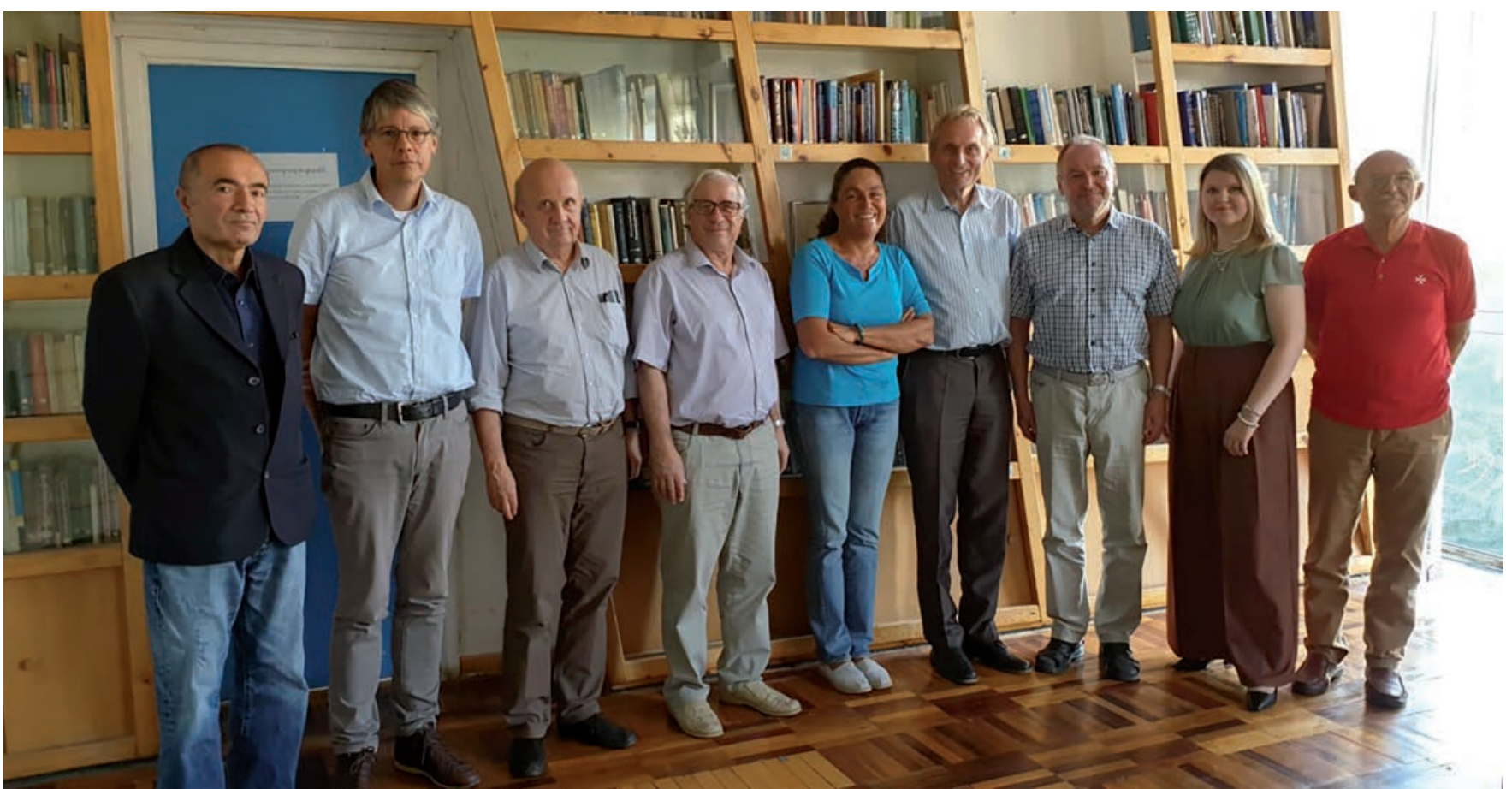

From left to right: Yuri Movsisyan (President of the Armenian Mathematical Union), Sjoerd Verduyn Lunel (EMS Secretary), Stefan Jackowski (EMS Executive Committee), Armen Sergeev (EMS Vice-President), Betiil Tanbay (EMS Vice-President), Volker Mehrmann (EMS President), Mats Gyllenberg (EMS Treasurer), Elvira Hyvönen (EMS Secretariat), Valentin Zagrebnov (Editor-in-Chief of EMS Newsletter). 
national Mathematical Union. It was agreed in the ensuing discussion that she will also oversee the compilation of a celebratory booklet on the history and mission of the EMS to mark its 30th anniversary in 2020.

The Executive Committee approved the list of 124 new individual members (including several under the EMS's new lifetime membership scheme) and one new institutional member. It then discussed possible action against two member societies who are in arrears on their dues and non-responsive to the President's letters.

\section{EMS website and news}

With the renewed EMS publishing house (EMS Press) now up and running, its CEO André Gaul has performed a thorough analysis of the systems and tools it uses, including its online presence. With the EMS webpage also due for renewal, the EC made several significant decisions regarding the future. It agreed to adopt a single design and technology with two webpages, and to reorganise the present content. It agreed that the EMS Press should take the lead on technical side of the webpage renewal, and that it is now appropriate to reconfigure the society's various information channels: the news webpage, the quarterly e-news, and this EMS Newsletter. On this topic, it decided to transform the Newsletter into a new EMS Magazine concentrating on articles and interviews, and separate from the daily news that will continue to be available through the EMS webpage. The EMS Magazine will follow an 'online first' protocol: features will be published online immediately that they ready, and every three months an EMS Magazine will be compiled these already published articles.

The EC discussed a report from the Publicity Officer Richard Elwes (who had presented his apologies), which noted that the EMS now has over 5000 followers on Twitter (https://twitter.com/EMSnewsletter) and over 3000 on Facebook (https://www.facebook.com/EMSnewsletter/).

\section{Scientific meetings}

Since its inception in 1992, the quadrennial European Congress of Mathematics (ECM) has been the EMS's headline event. The eighth instalment will take place in Slovenia, in July 2020 (https://www.8ecm.si/). The President reported on his recent visit to the site, and the committee discussed the ongoing preparations for this important occasion.

Looking further ahead, the committee considered the two live bids to organize the 9th ECM in 2024. These will each present their bid to the EMS Council in 2020 (directly before ECM8), where a final decision will be made by a vote by the Council delegates.

Vice-President Armen Sergeev then reported on the third Caucasian Mathematics Conference (CMC-III) that took place in Rostov-on-Don (Russia) in August 2019 and updated the EC about plans for CMC-IV to be held in Yerevan in 2021. There are also discussions about the possibility of a similar series to be held in the Balkans.

The President gave an update on a planned EuroPacific conference in 2021, and a proposed joint meeting of the EMS with the Indian Mathematics Consortium (TIMC) in India, also in 2021.

\section{Society matters}

The EMS Council is our society's governing body, and meets every two years. Its next meeting is in July 2020 in Bled (Slovenia), immediately prior to the ECM. The EC discussed preparations for this, both of a practical nature, and in terms of policies to be put to the council for a vote. These include a proposal for a formal structure through which young mathematicians can gain a voice in the society, and for the possible creation of special interest groups within the EMS.

The EC further agreed to invite representatives of the American Mathematical Society and International Mathematical Union as guests at the Council and ECM, and to extend an invitation to the ECM to other societies with which the EMS has reciprocity agreements (Australia, Canada and Japan).

The EC also discussed preparation for the upcoming annual meeting of Presidents of EMS Member Societies, which will take place in March 2020 at CIRM (France).

\section{Standing committees, projects, and publishing}

The EC made several appointments to EMS committees in need of renewal, before considering reports from the chairs or liaison officers of the committees for Applied Mathematics, Developing Countries (which administers the programmes Simons For Africa and ERCE Emerging Regional Centres of Excellence), Education, Ethics (a particular focus was the EMS Code of Practice, and the scope of its adherence among member societies), European Solidarity, Meetings, Publishing and Electronic Dissemination, and Women in Mathematics. Following the last of these, the EC agreed to allocate a specific budget for activities of the Women in Mathematics committee.

The EC then discussed several projects with which the EMS is involved including the online Encyclopedia of Mathematics (www.encyclopediaofmath.org) with which EMS Press is expecting to become involved, EUMATHS-IN (European Service Network of Mathematics for Industry and Innovation), and the Global Digital Mathematics Library.

The President presented an update on the progress of EMS Press. Although the new organisation is up and running in Berlin, there will be a transition period while the previous business is wound up. Valentin Zagrebnov as Editor-in-Chief of the Newsletter then presented his report, which the committee received with thanks. A report from Klaus Hulek, Editor-in-Chief of Zentralblatt Math was also received, and the President updated the EC about the German government's plan to facilitate its transition to open access in 2021.

\section{Funding, political, and scientific organisations}

The President reported on the latest developments regarding Horizon 2020 and reiterated the importance of the mathematics community speaking with one voice in all discussions with decision-makers. The President then 
gave an update on developments at the ERC (European Research Council), with former EMS President JeanPierre Bourguignon coming to the end of his tenure as President. In the ensuing discussion the EC considered the funding needs of mathematics, and the ERC's approach to these.

The next ESOF (European Science Open Forum) meeting will be in 2020 in Trieste (simultaneous with and nearby to ECM8). It is expected that the EMS Committee on Raising Public Awareness of Mathematics will organize a session there.

The President gave a brief update on recent developments regarding FAIRMAT (FAIR Mathematical Data for the European Open Science Cloud) as well as Plan S on open access.

The EC discussed the EMS's relationship with other mathematical organisations, including the IMU (Inter- national Mathematical Union), ICIAM (International Council for Industrial and Applied Mathematics), CIMPA (Centre International de Mathématiques Pures et Appliquées), the Bernoulli Society, the Banach Center, TICMI (Tbilisi International Center of Mathematics and Informatics), Oberwolfach, ECMI (the European Consortium for Mathematics in Industry), and the Abel Prize.

\section{Close}

The Executive Committee's next meeting will be in March 2020 at CIRM (France), followed immediately by the annual meeting of Presidents of EMS Member Societies. The meeting then closed with expressions of gratitude to Yerevan State University, the Armenian Mathematical Union, and to its President Yuri Movsisyan, for their magnificent hospitality and excellent organisation. 